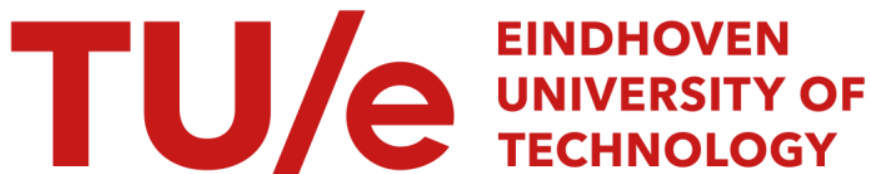

\section{Soliton propagation in micron-sized magnetic ratchet elements}

\section{Citation for published version (APA):}

Lee, J. H., Petit, D., Lavrijsen, R., Fernandez-Pacheco, A., Mansell, R., \& Cowburn, R. P. (2014). Soliton propagation in micron-sized magnetic ratchet elements. Applied Physics Letters, 104, [232404].

https://doi.org/10.1063/1.4882640

DOI:

10.1063/1.4882640

Document status and date:

Published: 01/01/2014

\section{Document Version:}

Publisher's PDF, also known as Version of Record (includes final page, issue and volume numbers)

\section{Please check the document version of this publication:}

- A submitted manuscript is the version of the article upon submission and before peer-review. There can be important differences between the submitted version and the official published version of record. People interested in the research are advised to contact the author for the final version of the publication, or visit the $\mathrm{DOI}$ to the publisher's website.

- The final author version and the galley proof are versions of the publication after peer review.

- The final published version features the final layout of the paper including the volume, issue and page numbers.

Link to publication

\section{General rights}

Copyright and moral rights for the publications made accessible in the public portal are retained by the authors and/or other copyright owners and it is a condition of accessing publications that users recognise and abide by the legal requirements associated with these rights.

- Users may download and print one copy of any publication from the public portal for the purpose of private study or research.

- You may not further distribute the material or use it for any profit-making activity or commercial gain

- You may freely distribute the URL identifying the publication in the public portal.

If the publication is distributed under the terms of Article 25fa of the Dutch Copyright Act, indicated by the "Taverne" license above, please follow below link for the End User Agreement:

www.tue.nl/taverne

Take down policy

If you believe that this document breaches copyright please contact us at:

openaccess@tue.nl

providing details and we will investigate your claim. 


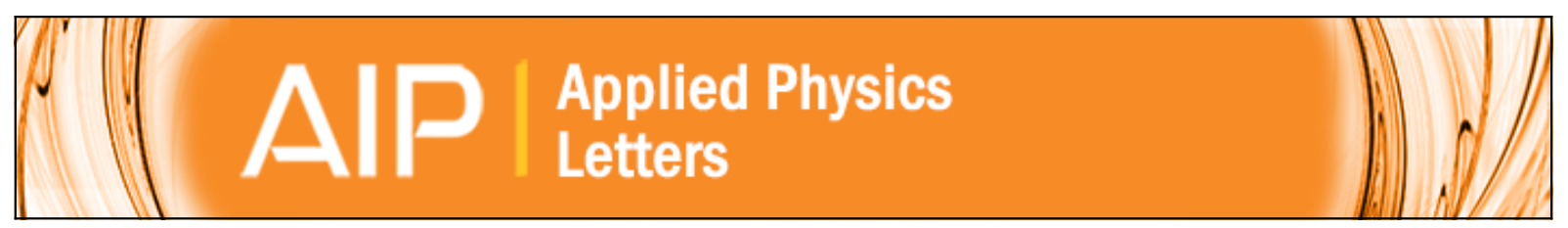

\section{Soliton propagation in micron-sized magnetic ratchet elements}

J. H. Lee, D. Petit, R. Lavrijsen, A. Fernández-Pacheco, R. Mansell, and R. P. Cowburn

Citation: Applied Physics Letters 104, 232404 (2014); doi: 10.1063/1.4882640

View online: http://dx.doi.org/10.1063/1.4882640

View Table of Contents: http://scitation.aip.org/content/aip/journal/apl/104/23?ver=pdfcov

Published by the AIP Publishing

\section{Articles you may be interested in}

Influence of reference layer stability on the switching performance of sub-micron-sized magnetic tunnel junctions J. Appl. Phys. 99, 08 K704 (2006); 10.1063/1.2176240

Magneto-optical properties of $\mathrm{Fe} / \mathrm{Cr} / \mathrm{Fe} / \mathrm{MgO} / \mathrm{Fe}$ structures epitaxially grown on $\mathrm{GaAs}(001)$

J. Appl. Phys. 95, 597 (2004); 10.1063/1.1632016

Magnetization reversal and domain structure of antiferromagnetically coupled submicron elements J. Appl. Phys. 93, 7441 (2003); 10.1063/1.1539074

Two-dimensional magnetic switching of micron-size films in magnetic tunnel junctions Appl. Phys. Lett. 76, 622 (2000); 10.1063/1.125838

Low-field magnetoresistance in magnetic tunnel junctions prepared by contact masks and lithography: $25 \%$ magnetoresistance at $295 \mathrm{~K}$ in mega-ohm micron-sized junctions (abstract)

J. Appl. Phys. 81, 5521 (1997); 10.1063/1.364588

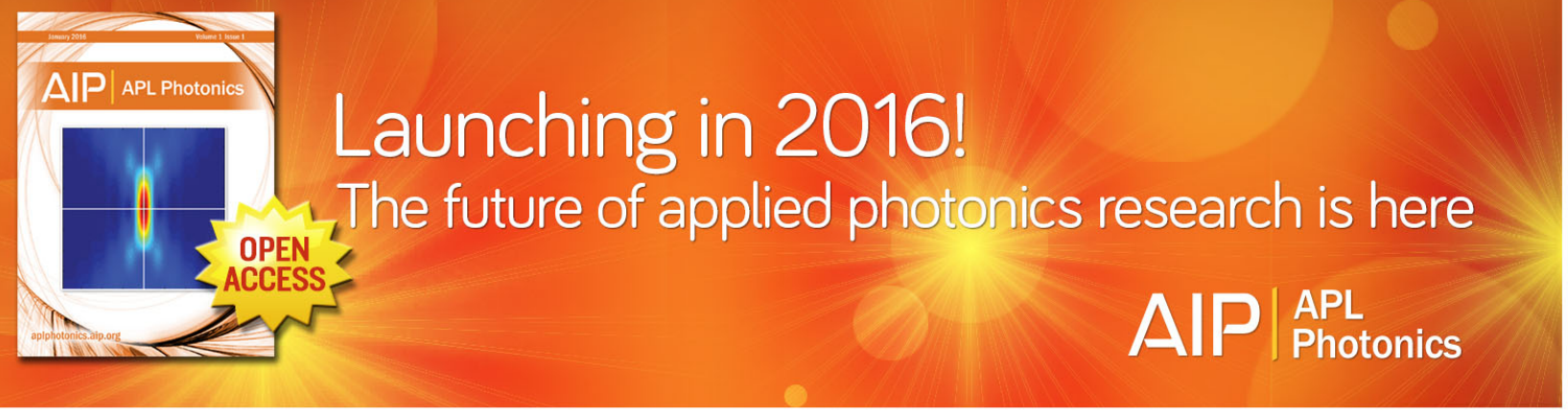




\title{
Soliton propagation in micron-sized magnetic ratchet elements
}

\author{
J. H. Lee, D. Petit, R. Lavrijsen, A. Fernández-Pacheco, R. Mansell, and R. P. Cowburn \\ Department of Physics, University of Cambridge, J J Thomson Avenue, Cambridge CB3 OHE, United Kingdom
}

(Received 30 April 2014; accepted 23 May 2014; published online 10 June 2014)

\begin{abstract}
We demonstrate ratchet soliton propagation in individual patterned antiferromagnetically coupled superlattice elements down to $3 \mu \mathrm{m}$ diameter using magneto-optical Kerr effect measurements. The bulk switching and soliton propagation fields are investigated as a function of the element size. It is found that on the length scale investigated here we do not see significant variation in ratchet behavior depending on the element size. The margin for soliton propagation and additional features related to downscaling are discussed. (C) 2014 AIP Publishing LLC. [http://dx.doi.org/10.1063/1.4882640]
\end{abstract}

The continuous miniaturization of data storage and logic devices has been one of the great technological successes of the past few decades. However, the limits of 2D scaling will be reached in a relatively short timescale and new directions for functional devices are being sought. ${ }^{1}$ One promising direction is to increase the density of devices by moving towards 3D devices. Already some flash memory modules are made with an explicitly $3 \mathrm{D}$ architecture. ${ }^{2}$ However, this approach essentially stacks devices on top of each other rather than exploiting new functionalities that can be gained from truly $3 \mathrm{D}$ devices. ${ }^{3-6}$ Recently, we demonstrated a magnetic soliton ratchet which can transfer magnetic information vertically on atomic length-scales. ${ }^{7}$ In this scheme, a soliton is formed at the junction between the two possible antiparallel domains ${ }^{8}$ which form the degenerate ground state of the system: a superlattice (SL) of anti-ferromagnetically coupled perpendicularly magnetized ultra-thin $\mathrm{CoFeB}$ layers. The ratchet behavior was achieved by tuning the magnetic layer thickness $\left(t_{1}, t_{2}\right)$ and the interlayer exchange coupling strength $\left(J_{1}, J_{2}\right)$ in an alternating manner., ${ }^{7,9}$ The ratchet effect was initially demonstrated on continuous films and theoretical calculations showed that such solitons can propagate in submicron structures. ${ }^{7}$ However, the experimental scaling of magnetic ratchet soliton propagation in patterned elements was not investigated. This is an important next step as it will determine the feasibility of using the soliton ratchet technique in industrial scale integrated circuits.

In this Letter, we report on experimental soliton propagation in perpendicularly magnetized individual micronsized dots with single shot measurements. The soliton propagation fields and bulk switching fields are measured as a function of dot size using the magneto-optical Kerr effect (MOKE). Furthermore, we discuss operating margins within patterned magnetic structures based on the experimental results.

The superlattice studied consists of $\mathrm{CoFeB}$ layers with $\mathrm{Pt} / \mathrm{Ru} / \mathrm{Pt}$ spacers on a Ta $(4 \mathrm{~nm}) / \mathrm{Pt}(20 \mathrm{~nm})$ buffer grown by DC magnetron sputtering onto oxidized $\mathrm{Si}$ substrates at a base pressure of $\sim 3 \times 10^{-8}$ millibars with an Ar pressure of $\sim 8 \times 10^{-3}$ millibars at room temperature. A schematic of the soliton propagation region of the studied superlattice is shown in Fig. 1(a). Various sizes of dots $(1 \mu \mathrm{m}-30 \mu \mathrm{m})$ were patterned on the perpendicularly magnetized antiferromagnetically coupled film by e-beam followed by thermal evaporation of $12 \mathrm{~nm} \mathrm{AlO}_{\mathrm{x}}$ and lift-off. The film was then ion milled to transfer the pattern to the superlattice. Figure 1(b) shows scanning electron microscope images of the dots, which have a repetition distance of at least $20 \mu \mathrm{m}$ in order to prevent interaction between the magnetic elements. Polar MOKE measurements (laser spot size of $5 \mu \mathrm{m}$ ) were performed at room temperature under magnetic fields, $H_{z}$, applied along the surface normal. The distance between dots and the small laser spot make it possible to measure individual dots.

The ratchet scheme, described in more detail in Refs. 7 and 10 , relies on an alternating sequence of magnetic layer thicknesses, $t_{1}$ and $t_{2}$, and interlayer couplings, $J_{1}$ and $J_{2}$. This scheme relies on the engineered difference between three switching fields, which are functions of $t_{1}, t_{2}, J_{1}, J_{2}$ along with the layer coercivity, $H_{c}{ }^{7}$ The first two are the soliton propagation fields: (1) $H_{p 1}$ is reached on increasing the magnetic field from remanence and is given by $H_{p 1}=H_{c}+\left(J_{1}-J_{2}\right) / t_{2}$ and (2) $H_{p 2}$ is reached on decreasing the field, $H_{p 2}=-H_{c}+\left(J_{1}-J_{2}\right) / t_{1}$. Furthermore, antiferromagnetically coupled layers in the bulk of the device switch at $H_{b}=H_{c}+\left(J_{1}+J_{2}\right) / t_{2}$. In order for a soliton to propagate, the following condition should be satisfied: $H_{p 2}<H_{p 1}<H_{b}$. In this study, the parameters for the extended thin film are constant: $H_{c}=230 \mathrm{Oe}, J_{1}=650$ Oe nm, $J_{2}=180$ Oe nm, $t_{1}=0.7 \mathrm{~nm}$, and $t_{2}=0.8 \mathrm{~nm}^{7}$

Figures 1(c) and 1(d) show single-shot measurements in the extended film and in a single $3 \mu \mathrm{m}$ dot, respectively. All measurements were conducted with a field sweep rate of $1 \mathrm{kOe} / \mathrm{s}$. The black line is the major hysteresis loop and the red dotted line is the minor loop where layers M4 and M5 (see Fig. 1(a)) reverse sequentially for the first two steps $\left(H_{p 1}\right.$ and $\left.H_{p 2}\right)$ of soliton propagation. ${ }^{7}$ The full process will be described later. Below $3 \mu \mathrm{m}$ (not shown here), no clear conclusion could be drawn from the measurements due to a low signal to noise ratio caused by the small volume of magnetic material in the $5 \mu \mathrm{m}$ laser spot.

The transitions marked with blue hash (\#) in Fig. 1(c) correspond to the switching of layers M5, M7, and M9 (see Fig. 1(a)). On comparing the major hysteresis loops of the extended film (Fig. 1(c)) and $3 \mu \mathrm{m}$ dot (Fig. 1(d)), an extra transition marked by the blue asterisk (*) is observed. At applied fields between -1000 Oe to -500 Oe, three layers switch together in the continuous film while two separate switches are seen in the $3 \mu \mathrm{m}$ dot. This is an indication that different layers in the stack may have different changes in behavior with patterning. The most likely cause is a change 
(a)

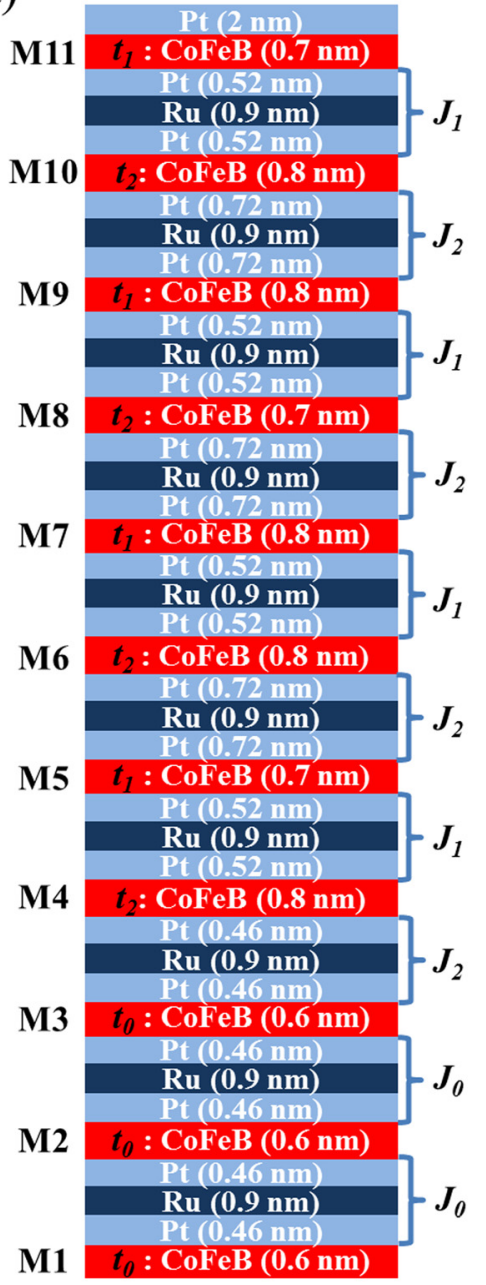

(b)

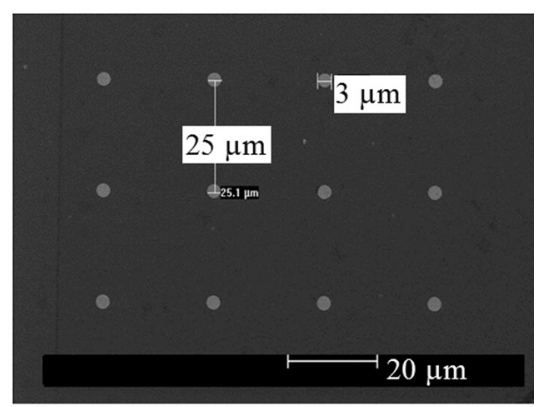

(c)

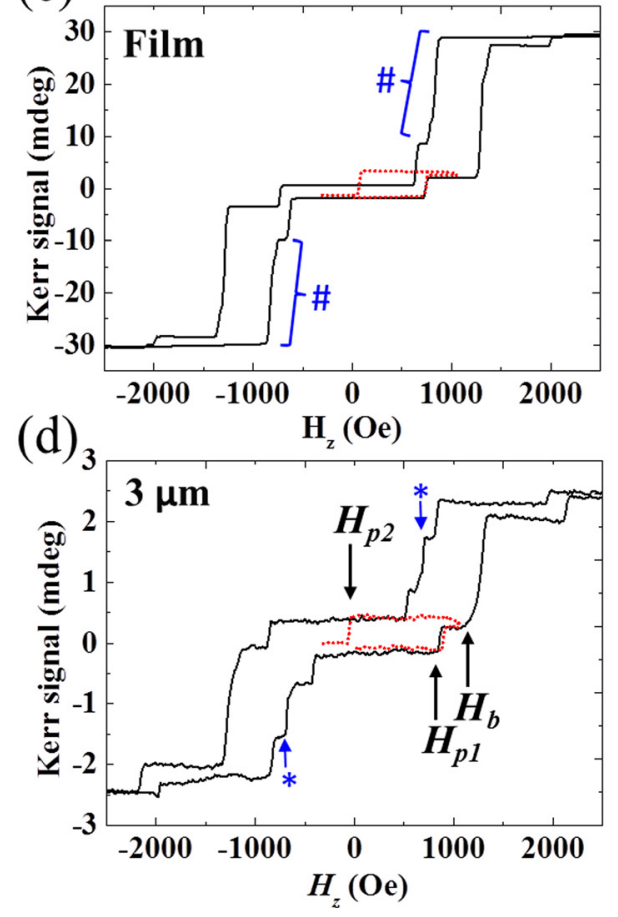

FIG. 1. (a) A schematic of the superlattice. (b) SEM images of patterned superlattice with spacing of $20 \mu \mathrm{m}$ and diameter of $3 \mu \mathrm{m}$. Major hysteresis loop (in black) and minor loop of the first two steps of soliton propagation (red dotted line) in (c) a continuous film and (d) a $3 \mu \mathrm{m}$ dot with singleshot measurements. of microstructure in layers higher up in the stack. This has been observed before by scanning transmission electron microscopy (STEM) imaging of similar stacks and leads to changes in domain structure during reversal of multiple nominally identical layers. ${ }^{11,12}$

In Fig. 2(a), we plot the three switching fields that characterize the ratchet, $H_{p 1}, H_{p 2}$, and $H_{b}$, as a function of dot size. Ten elements per size were measured and for each element, 10 loops were averaged. The plotted error is the standard deviation of the switching field measured across the 10 structures. We find that these values are nearly constant across the size range measured. As the dot size decreases, a slight upward trend in $H_{p 1}$ is seen with a slight downward trend in $H_{p 2}$. This implies that the underlying behavior of the layers is not strongly affected by patterning and that dipole fields are negligible at these length scales. ${ }^{13,14} \mathrm{We}$ expect that the $H_{b}$ transition will be most affected by interlayer dipole fields because for the $H_{b}$ transition the dipolar fields from the neighboring layers add together whereas for soliton propagation $\left(H_{p 1}, H_{p 2}\right)$ the dipole fields from neighboring layers partially cancel out. ${ }^{7}$ The interlayer dipole interactions are ferromagnetic, causing a reduction in the switching field, however for $3 \mu \mathrm{m}$ elements we only expect a decrease of the order of $\sim 10$ Oe (calculated by the macrospin approximation on square structures ${ }^{15}$ with $M_{s}=1.3 \times 10^{3} \mathrm{emu} / \mathrm{cm}^{3}$, magnetic layer thickness of $0.75 \mathrm{~nm}$ and the average distance between magnetic layers of $2.14 \mathrm{~nm}$ in our stack.). In general, patterning the film to the element sizes in the range
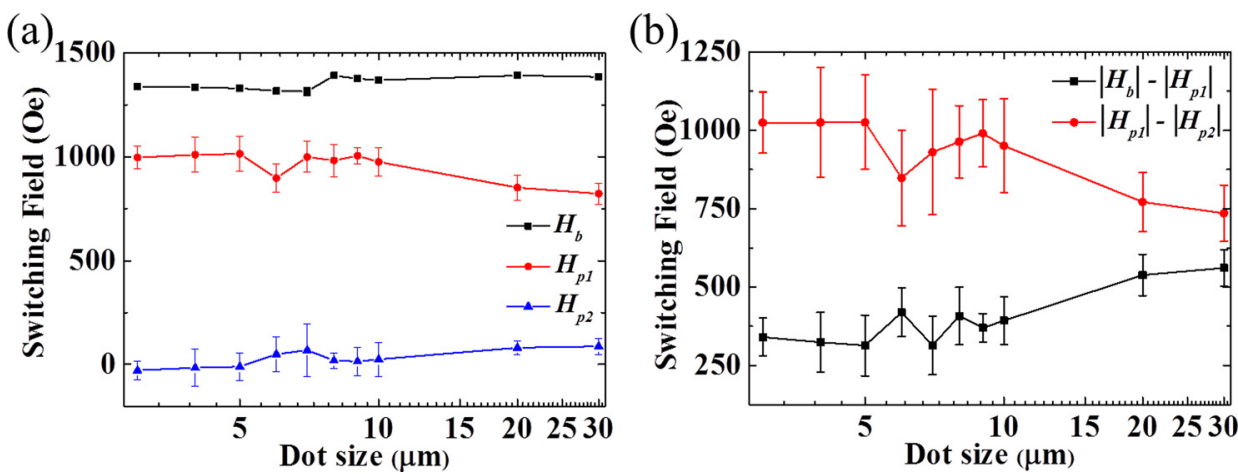

FIG. 2. Size dependence of (a) $\mathrm{H}_{\mathrm{b}}$, $\mathrm{H}_{\mathrm{p} 1}$, and $\mathrm{H}_{\mathrm{p} 2}$, (b) operating margins. In the case of $\mathrm{H}_{\mathrm{b}}$, the error bar is smaller than points in the graph. 
studied here leads to increases in $H_{c},{ }^{12,13,16}$ whilst the strength of the interlayer couplings is likely to decrease due to edge effects. ${ }^{12,17,18}$ However, within the errors of the measurement, $H_{c}$ and interlayer coupling remain constant as a function of size in this study.

In order to propagate a soliton in a stack, there are two conditions which need to be met. First, it is required that $\left|H_{b}\right|>\left|H_{p 1}\right|$ (i.e., $2 J_{2} / t_{2}>0$ ), and second, $\left|H_{p 1}\right|>\left|H_{p 2}\right|$ (i.e., $\left.2 H_{c}>\left(J_{1}-J_{2}\right)\left(t_{2}-t_{1}\right) /\left(t_{1} t_{2}\right)\right)$. The first equation indicates that the soliton propagation field should be lower than the bulk switching field. The second equation gives the condition for correct unidirectional behavior. These equations give the margin of soliton operation as shown in Fig. 2(b). As the dot size becomes smaller, $\left|H_{b}\right|-\left|H_{p 1}\right|$ tends to decrease while $\left|H_{p 1}\right|-\left|H_{p 2}\right|$ increases. This indicates that as the element size becomes smaller, the first step $\left(H_{p l}\right)$ for soliton propagation is more susceptible to failure rather than the second one $\left(H_{p 2}\right)$. In these measurements, this is due to the increase in $H_{p 1}$. Although, from simulations, we expect increased interlayer dipole coupling to be the cause for failure of the ratchet scheme in the $100 \mathrm{~nm}$ range, this is due to a reduction in $\mathrm{H}_{b}$ rather than an increase in $\mathrm{H}_{p 1}{ }^{7}$

Having discussed the first two steps of soliton propagation, which involves only layers M4 and M5, we now turn to full soliton propagation. In order to observe soliton propagation along the 8 layers composing the propagation region of the stack (four $H_{p 1}-H_{p 2}$ steps), we used the square pulse sequence presented as a red line in Fig. 3(a). The applied field sequence is as follows: the first negative high amplitude saturation field pulse (i) was applied to initialize the stack and inject the soliton upon decreasing the field back to zero. This was followed by four positive field pulses (ii-v) which propagate solitons. Two more additional positive field pulses (vi-vii) were applied to confirm that the soliton is expelled.
After that the same sequence was applied using the opposite sign of field pulses (a high positive saturation field pulse and negative propagation field pulses) in order to propagate a soliton of the opposite polarity. For the patterned dots, due to the increased field required to reach $\mathrm{H}_{\mathrm{p} 1}$, up to $15 \%$ higher amplitude applied fields were used. In Figs. 3(b)-3(e), the corresponding MOKE signal for the continuous film, $10 \mu \mathrm{m}$, $5 \mu \mathrm{m}$, and $3 \mu \mathrm{m}$ dots are shown. As the soliton propagates up the stack, the level of the MOKE signal increases (positions (2), (4), (6), and (8)). The corresponding magnetic configurations are presented in Fig. 3(f). ${ }^{7}$ We see evidence of soliton propagation down to the $3 \mu \mathrm{m}$ dot as seen by the changing of levels, in particular, the expulsion of the soliton seen in the change of the level between (7) and (9) in Fig. 3(b) (marked by the magenta dotted line in Figs. 3(c)-3(e)). The data shown are corrected for drift during the time of the measurement ( $\sim 20 \mathrm{~s})$. As observed, there are several features that change with size. Due to the reduction in signal to noise ratio, the changes in levels, particularly the odd-numbered states, become less clear. Instead of a continuous reduction in the MOKE level for the first three $H_{p 2}$ transitions (positions (3), (5), and (7) as seen in Figure 3(b), we see an increase in signal at position 7 in Figs. 3(c) and 3(d). We attribute a change of the level between positions (5) and (7) to optical effects associated with diffraction and optical skin depth, which become more pronounced for the smaller dots when the wavelength of the laser is similar to the structure size. The final upward jump (8) of the top layer switching is still clearly seen though, which suggests correct operation of the ratchet. The trend in the increasing signal on even-numbered switches is more clearly retained throughout. Also, we see that as the size of the dots reduces, unwanted switching of the top layer after soliton expulsion, marked by the blue plus $(+)$ becomes more pronounced. In the thin film, there is a
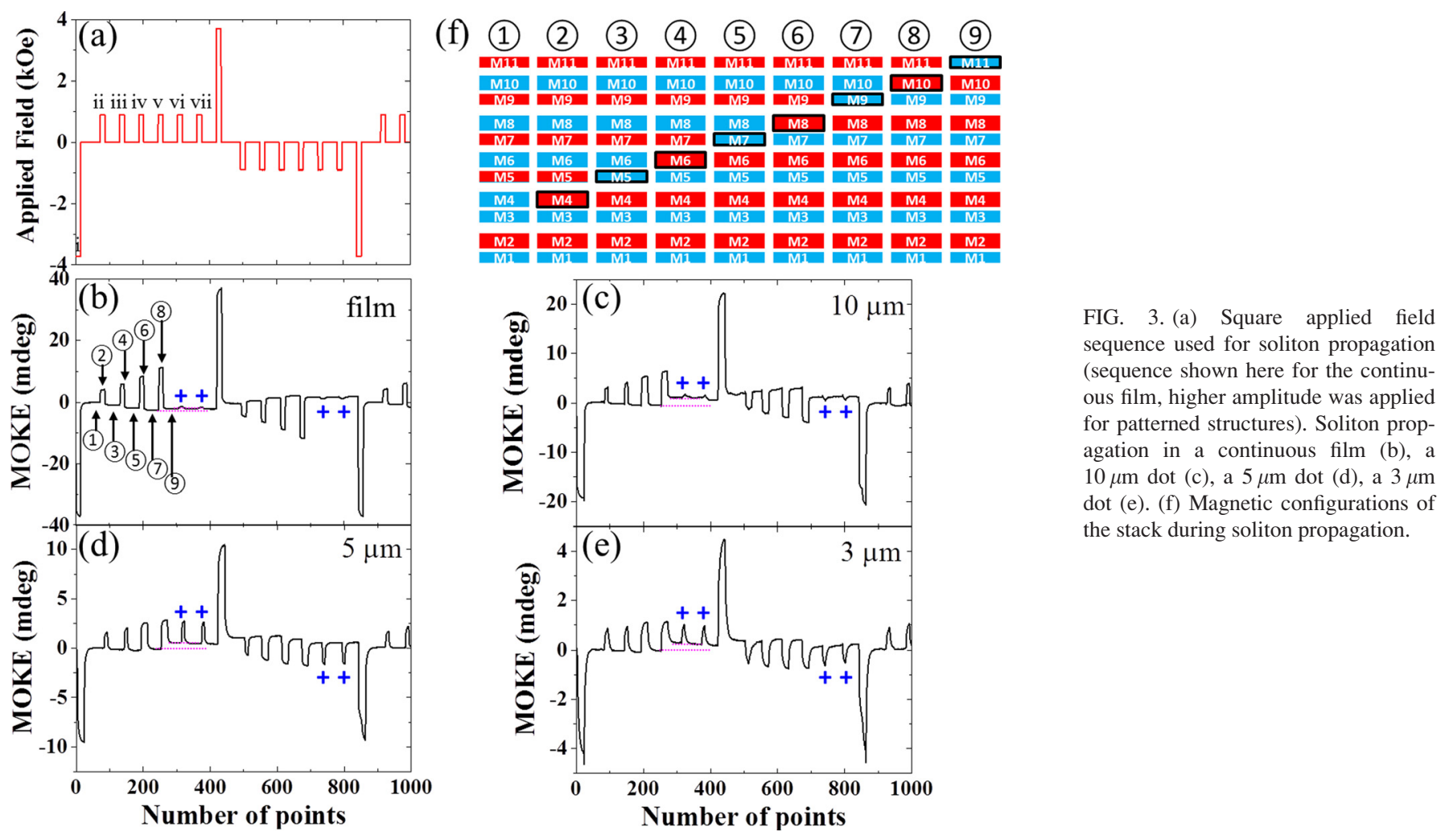

FIG. 3. (a) Square applied field for soliton propagation ous film, higher applied for patterned structures). Soliton propa continuous film (b), a dot (e). (f) Magnetic configurations of

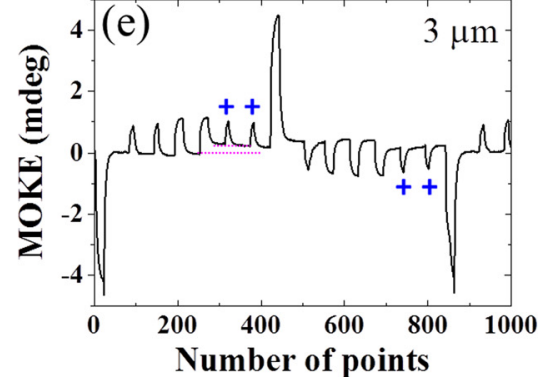


weak response of the top layer which changes into full switching for the $3 \mu \mathrm{m}$ and $5 \mu \mathrm{m}$ films. Flipping of the top layer after soliton expulsion was observed in our previous experiments. ${ }^{10}$ This can be understood in the following terms: as discussed in the previous section, the field required to reach the $H_{p 1}$ transition increases by $15 \%$ (for $3 \mu \mathrm{m}$ dots compared to the continuous film) with decreasing dot size. If the top layer coercivity does not change as strongly as the other layers in the stack, it will tend to switch after soliton expulsion more easily. In addition, from a previous study, ${ }^{11}$ it was found that the top layer of the stack is discontinuous to a certain extent due to poor growth. This may lead to a smaller coercivity change with patterned size compared to other layers. This, combined with the increased applied fields, makes this layer more likely to switch in smaller patterned structures.

In summary, we have investigated soliton propagation in a series of micron size individual dots. Size dependence of the switching fields, $H_{p 1}, H_{p 2}$, and $H_{b}$, were measured using MOKE measurements. We see no large changes in the measured parameters $H_{p 1}, H_{p 2}$, and $H_{b}$. This is expected for these lengths scales, as interlayer dipole couplings are small. Furthermore, the two margins $\left(\left|H_{b}\right|-\left|H_{p 1}\right|,\left|H_{p 1}\right|-\left|H_{p 2}\right|\right)$ for soliton propagation were extracted and indicate that the first propagation step $\left(H_{p 1}\right)$ is the more likely step for the failure of soliton propagation. Soliton propagation down to $3 \mu \mathrm{m}$ lateral size elements was demonstrated. This work shows that micron-scale 3-dimensional spintronic devices with good operating margins are feasible. Future work will focus on sub-micron devices.

This research is funded by the European Community under the Seventh Framework Program ERC Contract No. 247368: 3SPIN and the Netherlands Organization for
Scientific Research and Marie Curie Cofund Action (NWORubicon 680-50-1024 and VENI 680-47-428).

${ }^{1}$ See http://public.itrs.net/ for 2D scaling device limits and new directions for future devices.

${ }^{2}$ S.-M. Jung, J. Jang, W. Cho, H. Cho, J. Jeong, Y. Chang, J. Kim, Y. Rah, Y. Son, J. Park, M.-S. Song, K.-H. Kim, J.-S. Lim, and K. Kim, in International Electron Devices Meeting, 2006 (IEDM '06) (IEEE, 2006), p. 1.

${ }^{3}$ S. S. P. Parkin, M. Hayashi, and L. Thomas, Science 320, 190 (2008).

${ }^{4}$ A. Fernández-Pacheco, D. Petit, R. Mansell, R. Lavrijsen, J. H. Lee, and R. P. Cowburn, Phys. Rev. B 86, 104422 (2012).

${ }^{5}$ E. Y. Vedmedenko and D. Altwein, Phys. Rev. Lett. 112, 017206 (2014).

${ }^{6}$ A. Fernández-Pacheco, L. Serrano-Ramón, J. M. Michalik, M. Ricardo Ibarra, J. M. De Teresa, L. O'Brien, D. Petit, J. Lee, and R. P. Cowburn, Sci. Rep. 3, 1492 (2013).

${ }^{7}$ R. Lavrijsen, J.-H. Lee, A. Fernández-Pacheco, D. C. M. C. Petit, R. Mansell, and R. P. Cowburn, Nature 493, 647 (2013).

${ }^{8}$ V. G. Baryakhtar, M. V. Chetkin, B. A. Ivanov, and S. N. Gadetskii, Dynamics of Topological Magnetic Solitons, Experiments and Theory Vol. 129 (Springer, Berlin, 1994).

${ }^{9}$ R. Lavrijsen, A. Fernández-Pacheco, D. Petit, R. Mansell, J. H. Lee, and R. P. Cowburn, Appl. Phys. Lett. 100, 052411 (2012).

${ }^{10}$ R. Lavrijsen, D. C. M. C. Petit, A. Fernández-Pacheco, J. H. Lee, R. Mansell, and R. P. Cowburn, Nanotechnology 25, 105201 (2014).

${ }^{11}$ J.-H. Lee, R. Mansell, D. Petit, A. Fernández-Pacheco, R. Lavrijsen, and R. P. Cowburn, Spin 3, 1340013 (2013).

${ }^{12}$ J. M. Shaw, H. T. Nembach, and T. J. Silva, J. Appl. Phys. 108, 093922 (2010).

${ }^{13}$ T. Thomson, G. Hu, and B. D. Terris, Phys. Rev. Lett. 96, 257204 (2006).

${ }^{14}$ V. Baltz, A. Bollero, B. Rodmacq, B. Dieny, J.-P. Jamet, and J. Ferré, Eur. Phys. J. Appl. Phys. 39, 33 (2007).

${ }^{15}$ G. Akoun and J.-P. Yonnet, IEEE Trans. Mag. 20, 1962 (1984).

${ }^{16}$ J. E. Davies, P. Morrow, C. L. Dennis, J. W. Lau, B. McMorran, A. Cochran, J. Unguris, R. K. Dumas, P. Greene, and K. Liu, J. Appl. Phys. 109, 07B909 (2011).

${ }^{17}$ J. Moritz, F. Garcia, J. C. Toussaint, B. Dieny, and J. P. Nozières, Europhys. Lett. 65(1), 123 (2004).

${ }^{18} \mathrm{~S}$. Boukari, J. Venuat, A. Carvalho, J. Arabski, and E. Beaurepaire, J. Appl. Phys. 104, 113907 (2008). 